\title{
On some new compounds of chlorine
}

\section{Mons. H. Rose}

To cite this article: Mons. H. Rose (1838) On some new compounds of chlorine, Philosophical Magazine Series 3, 12:73, 220-220, DOI: 10.1080/14786443808649416

To link to this article: http://dx.doi.org/10.1080/14786443808649416

册 Published online: 01 Jun 2009.

6 Submit your article to this journal $\pi$

LII Article views: 2

Q View related articles $₫$ 
ON SOME NEW COMPOUNDS OF CHLORINE. BY MONS. H. ROSE.

Hitherto the composition of the volatile compounds of chlorine has been determined by means of the known composition of the oxide or oxacid, formed by the decomposition of water, at the same time as hydrochloric acid. Since, however, the discovery of chromate of chloride of chromium, $\left(2 \ddot{\mathrm{Cr}}+\mathrm{Cr} \mathrm{Cl}^{3} \text {, }\right)^{*}$ it is no longer possible to apply the same mode of determination to the composition of all the volatile compounds of chlorine, and it became necessary to submit to a quantitative analysis such of these combinations, in the formation of which a substance containing oxygen was employed. M. Rose, proceeding on this principle, has discovered that the two bodies which are formed by the reaction of chlorine gas upon the oxides of tungsten and molybdena, the chloride of tungsten and the chloride of molybdena, possess a composition analogous to the chromate of chloride of chromium. As they are converted into hydrochloric acid, and tungstic or molybdic acid, when treated with water, it was supposed that their composition was analogous to that of the two last acids. In fact, during the preparation of chloride of tungsten there is obtained, besides the chloride, another more volatile chloride corresponding to the oxide of the same metal, and also a tungstic acid which is not volatile. The same products, formed by the decomposition of the chloride, appear when it is suddenly exposed to a strong heat. Thus, it is not entirely composed of tungsten and chlorine, but must contain oxygen; the volatile compound cannot, however, be obtained perfectly free from excess of tungstic acid, which mixes with it during its formation. The same happens with hyperchloride of molybdena as with chloride of tungsten ; their composition may therefore be represented by $2 \dddot{\mathrm{W}}+\mathrm{W} \mathrm{Cl}^{3}$ and by Mo $\mathrm{Cl}^{3}$.

The chromate of chloride of chromium, above described, is the result of the reaction of chromate of potash, chloride of sodium, and sulphuric acid. If, instead of employing chloride of sodium, bromide of sodium or potassium be substituted for it, bromine is obtained quite free from chromium. This difference of reaction admits of the detection of slight traces of a metallic chloride in large quantities of metallic bromides, which would otherwise be extremely difficult. If bromide of potassium or sodium be submitted to distillation with chromate of potash and sulphuric acid, and if the product of the distillation be received in ammonia, no trace of chromium will be found in it, if the salt was quite free from chloride of potassium or sodium. - Journal de Chimie Médicale, December 1837.

\section{NEW ACID FORMED BY THE COMBUSTYON OF ALCOHOL AROUND AN INCANDESCENT PLATINA WIRE.}

M. Leroy states that this acid is liquid, and of a consistence similar to that of the oil of sweet almonds or olives, and that it is perfectly limpid. It is greasy and unctuous to the touch; it spots paper like.

* See Mr. Walter's'paper, p. 83 of our last number. 